Marina Ščerbakova, ${ }^{*}$ Sinitsin P.A., Porjadina G.I.

\title{
METABOLIČKI SINDROM KOD DECE I ADOLESCENATA
}

Sažetak: Metabolički sindrom (MS) predstavlja kompleks uzajamno povezanih promena metabolizma ugljenih hidrata i masti, mehanizma regulacije krvnog pritiska i endotelne funkcije, koje nastaju usled neuro-endokrine disfunkcije u uslovima snižene osetljivosti tkiva prema insulinu - tzv. insulinske rezistencije.

Prema savremenim shvatanjima, kompleks simptoma MS uključuje: insulinsku rezistenciju i hiperinsulinemiju, abdominalno-visceralnu gojaznost, primarnu arterijsku hipertenziju, narušenu toleranciju prema glukozi ili dijabetes tipa 2, dislipidemiju aterogenog vektora, hiperurikemiju i podagru, promene hemostaze predtrombotičkog stanja, mikroalbuminuriju, ranu aterosklerozu / ishemijsku bolest srca.

Uzimajući u obzir koncepciju eksperata Međunarodnog udruženja za dijabetes (IDF) o odgovornoj ulozi abdominalno-visceralne gojaznosti u dijagnostici MS, sproveli smo ispitivanje moskovske populacije dece i adolescenata, sa zajedničkim kriterijumom selekcije - gojaznošću. Svrha našeg ispitivanja je bila određivanje prirode i učestalosti promena, svojstvenih metaboličkom sindromu. Za cilj smo uzeli utvrđivanje stepena zavisnosti između kliničko-laboratorijskih promena kod metaboličkog sindroma i varijanti polimorfizma određenih gena kod dece sa gojaznošću.

Iz anamnestičkih podataka se saznaje da srednji uzrast izraženog porasta telesne mase (po 7+/-1.5 kg godišnje) iznosi 10.5+/- 2.25 god. Nije utvrđena jasna korelacija između promena navika u ishrani i početka gojaznosti. Saglasno podacima iz anketa, ustanovljeno je da se u $65 \%$ slučajeva gojaznost razvila u vezi sa promenom načina života (smanjena fizička aktivnost) što je u $80 \%$ slučajeva bilo prisutno i kod roditelja i bliskih rođaka. Kod dece i adolescenata sa abdominalnom gojaznošću često su prisutne sledeće promene, karakteristične za MS: promene u

Medicinski fakultet, Moskva, Ruska Federacija. 
lipidnom statusu (48.3\%), statusu ugljenih hidrata (22.4\%) i jedinjenja purina $(19 \%)$ i epizodične promene u regulaciji arterijskog pritiska (43.1\%).

Rezultati genetskih ispitivanja i slična klinička slika osnovnih patoloških promena kod dece i bliskih rođaka (više od $66.6 \%$ slučajeva) govori u prilog velikog uticaja genetskih faktora na nastanak i kliničku izraženost gorenavedenih simptoma kod dece sa gojaznošću. Utvrđivanje nasledne predispozicije pomaže u objašnjavanju prisustva ili odsustva očekivanih promena, kao i blagovremenom prepoznavanju gojazne dece sa rizikom razvoja MS, u cilju određivanja mogućnosti i efikasnosti kako nemedikamentozne, tako i farmakoterapije.

Glavni cilj preventive i lečenja je nedopustiti ili smanjiti ukupni rizik razvoja i progresije kardiovaskularnih oboljenja, karakterističnih za MS. U dečjem uzrastu i kod adolescenata u prvi plan dolazi do iražaja preventiva formiranja i razvoja sastavnih komponenata metaboličkog sindroma. Na svim etapama su bitne aktivnosti u cilju formiranja zdravog načina života i obustave štetnih navika.

Метаболический синдром (МС) представляет собой комплекс взаимосвязанных нарушений углеводного и жирового обмена, механизмов регуляции артериального давления и функций эндотелия, формирующихся на фоне нейроэндокринной дисфункции, в условиях пониженной чувствительности тканей к инсулину - инсулинорезистентности (ИР). Считается, что все компоненты $\mathrm{MC}$ генетически обусловлены, а объединяющей основой данных проявлений является первичная ИР и сопутствующая ей системная гиперинсулинемия (ГИ), природа возникновения которых гетерогенна.

Подробное изучение отдельных звеньев МС началось ещё в 20-е годы прошлого века. Г.Ф.Ланг обратил внимание на «тесную взаимосвязь между артериальной гипертензией (АГ), ожирением, нарушением липидного и углеводного обмена и подагрой». E.Kylin в 1923 году описал синдром - «гипертензии - гипергликемии - гиперурикемии». В 1947 году J.Vague описал два типа распределения жировой ткани и отметил частое сочетание андроидного типа с инсулиннезависимым сахарным диабетом (СД II), ишемической болезнью сердца (ИБС) и подагрой [1,2]. J.Camus в 1966 году ввёл понятие «метаболического трисиндрома», включавшего в себя СД II, подагру и гиперлипидемию [3]. В 1967 году Avogaro P.,Crepaldi G. описали сочетание метаболических нарушений при ожирении, как «полиметаболический синдром» [4]. В 1988 году G. Reaven описал первичную ИР с последующей компенсаторной ГИ, нарушение толерантности к глюкозе (НТГ), дислипопротеинемию и АГ, объединив их в «метаболический синдром Х» [5,6]. В 1991 Р. Bjorntorp, указывает на основополагающую роль абдоминально-висцерального ожирения в 
развитии «цивилизационного синдрома» или «гормонально-метаболического синдрома» $[2,7]$.

В настоящее время в симптомокомплекс МС включены: ИР и гиперинсулинемия (ГИ), абдоминально-висцеральное ожирение, первичная артериальная гипертензия (АГ), нарушение толерантности к глюкозе (НТГ) или сахарный диабет второго типа (СД II типа), дислипидемия атерогенной направленности, гиперурикемия (ГУ) и подагра, нарушения гемостаза предтромботического характера, микроальбуминурия (МАУ), ранний атеросклероз/ишемическая болезнь сердца (ИБС).

Постоянное развитие и совершенствование методов и принципов научного исследования МС с одной стороны помогает объяснить природу возникновения и общий характер его проявлений, но, с другой стороны, это приводит к неизбежному увеличению количества компонентов, включаемых в состав МС и затрудняющих его диагностику. Наиболее удачное решение данной проблемы предложили эксперты международной ассоциации диабета (IDF), которые разработали чёткие и достаточно простые в применении критерии диагностики МС у взрослых (2005 год) и детей и подростков (2007 год) [8-10].

Исходя из концепции экспертов IDF об основополагающей роли абдоминально-висцерального ожирения в диагностике $\mathrm{MC}$, нам показалось интересным провести многоплановое исследование среди московской популяции детей и подростков, имеющих единый критерий отбора - ожирение, для установления характера и частоты обменных нарушений, свойственных МС.

Целью нашей работы стало выявление зависимости между клинико-лабораторными проявлениями обменных нарушений и вариантами полиморфизма отдельных генов у детей с ожирением.

\section{Материалы и методы}

Исследования проводились на базе Морозовской Детской Городской Клинической Больницы. Критерием отбора пациентов являлось ожирение. Было обследовано 116 детей с ожирением I - IV степени в возрасте от 6 до 17 лет: 87 мальчиков и 29 девочек. Дети распределились по возрасту следующим образом: 6 лет - 1 человек, 7 лет - 2 человека; 8 лет - 2; 9 лет - 6;. 10 лет - 12; 11 лет - 10; 12 лет - 20; 13 лет - 18; 14 лет - 23; 15 лет - 8; 16 лет - 11 и 17 лет - 3 человека. В методику обследования входило: Сбор анамнеза ребёнка, членов семьи и ближайших родственников (с уточнением наличия проявлений и осложнений ИБС, АГ, ожирения, нарушений обмена углеводов, липидов и пуриновых оснований). Измерение роста и массы тела. Степень ожирения определялась по проценту избытка массы в сравнении с долженствующей с использованием центильных таблиц для детей. Для оцен- 
ки применялись общепринятые показатели степеней ожирения: I - 10-25\%, II - 26-49\%, III - 50-99\%, IV - $\geq 100 \%$. У детей старшего школьного возраста учитывался индекс Кетле (ИМТ, кг/м²): 18,5-24,5 (нормальная масса тела); 25-29,9 (избыточная масса тела); 30-34,9 (соответствует I степени ожирения); 35-39,9 (соответствует II степени); $\geq 40$ (соответствует III степени). Для детей младшего и среднего школьного возраста использовались данные пограничных значений ИМТ, предложенных Katmarzyk P.T. [11]. Оценка окружности талии (ОТ) проводилась по сводной таблице данных пограничных величин для детей, взятой из того же источника (Katmarzyk P.T.), с учётом рекомендаций IDF от 2007 года ( $\geq 90$ перцентиля, либо $>80$ см у девочек и $>94$ см у мальчиков в возрасте 16 лет и старше) [10,11]. Регулярное измерение артериального давления (АД в мм.рт.ст.) при помощи тонометра и манжеты по методике Короткова на двух руках в течение 1,5 недель и его оценка с применением центильных таблиц для детей разного возраста, пола и роста (не должно превышать 95-го перцентиля) и учётом рекомендаций IDF от 2007 года ( $\geq 130 / 85$ мм.рт.ст) [10]. Всем детям проводилось комплексное обследование, включающее изучение липидного, углеводного спектров и обмена пуриновых оснований. Для определения нарушений в липидном спектре крови использовались следующие значения: по ОХС $>5,2$ ммоль/л, по ТГ $>1,7$ ммоль/л, по ХС ЛПНП >2,85 ммоль/л, по ХС ЛПВП < 1,03 ммоль/л для детей младше 16 лет и $<1,03$ ммоль/л у мальчиков и $<1,29$ ммоль/л у девочек в возрасте 16 лет и старше. Анализ сыворотки производился на аппарате Super Z Analyzer производства Mitsubishi Япония. Углеводный обмен исследовался при помощи: определения толерантности к глюкозе (методом перорального стандартного глюкозотолерантного теста (СГТТ), при котором уровень глюкозы капиллярной крови не должен превышать 7,8ммоль/л в контроле через 2 часа после нагрузки), в динамике исследовался уровень глюкозы капиллярной крови (при норме менее 5,6 ммоль/л натощак) с использованием глюкометра Accu-Chek ${ }^{\circledR}$ Active производства Roche Германия. Обмен пуриновых оснований оценивался по уровню мочевой кислоты (МК) в сыворотке крови на аппарате Super Z Analyzer. За пограничное значение МК был взят показатель 0,48 ммоль/л. ЭКГ исследование на аппарате MAC-1200 ST производства GE Medical Systems Германия. При выраженных ЭКГ изменениях проводилось ЭХО-КГ исследование на аппарате Sonoline G 50 производства Simens Германия. Пятьдесят человек (40 мальчиков и 10 девочек) были обследованы при помощи метода полимеразной цепной реакции (ПЦР) на I/D (Insertion-Deletion) полиморфизм гена АCE (ангиотензин-превращающий фермент - АПФ) и W/R (Trp64Arg) полиморфизм гена $\beta_{3}$-AR. Использовался амплификатор Biometra T3 Thermocycler германского производства, аппараты для проведения горизонтального и вертикального электрофореза Bio-Rad Sub-Cell®GT, выпускаемые в США. Проведён анализ клинико-лабораторных нарушений, 
характерных для МС, в зависимости от вариантов генотипа. Произведена оценка фенотипических сходств между детьми, чьи генотипы изучались, и их ближайшими родственниками.

\section{Результаты и их обсуждение}

Исходя из анамнестических данных, мы пришли к выводу, что средний

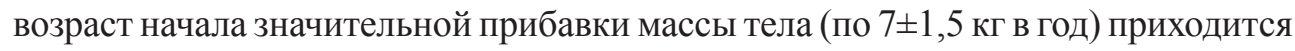
на 10,5 $\pm 2,25$ года и, как правило, не имеется чёткой зависимости между изменением пищевых привычек и началом ожирения. Так, по нашим результатам, только в 15\% случаев (17 человек: 14 мальчиков и 3 девочки) дети и их родители указывали на то, что избыточная прибавка массы тела явилась результатом чрезмерного потребления пищи, когда в 85\% (99 человек: 73 и 26) такой закономерности не наблюдалось. По результатам опроса мы определили, что в 65\% случаев (75: 60 и 15) развитие ожирения протекало на фоне изменения образа жизни в сторону гиподинамии, что в 80\% (60: 50 и 10) было спровоцированно аналогичным образом жизни родителей и ближайших родственников. По полученным данным, ожирение I степени имели 14 человек (12\%): 13 (14,9\%) и 1 $(3,4 \%)$; II - 47 человек (40,5\%): 37 (42,5\%) и 10 (34,5\%); III - 49 человек $(42,2 \%)$ : $34(39,1 \%)$ и $15(51,7 \%)$; IV - 6 человек $(5,17 \%): 3(3,4 \%)$ и $3(10,3 \%)$. Более $2 / 3$ пациентов (69\%) имели превышение по значению ОТ (80: $56(64 \%)$ и $24(82 \%))$, являющемуся патогномоничным признаком абдоминального ожирения. Эпизодическое повышение АД, связанное с эмоциональными и/или физическими нагрузками, отмечалось у 50 детей (43,1\%): 38 (43,7\%) и 12 (41,4\%). Стойкое повышение - у 23 человек (19,8\%): 17 (19,5\%) и 6 (20,7\%) в возрасте от 12 до 16 лет. Более того, среди детей со стойким повышением АД в 40\% случаев (9 человек: 7 и 3) было зафиксировано поражение органов мишеней. Самым частым из ранних поражений являлась ангиопатия сетчатки в виде суженных и извитых артерий и расширенных вен глазного дна - 80\% (7: 8 и 1). По 10\% пришлось на синусовую тахикардию и симтомы гипертрофии миокарда левого желудочка (по данным ЭКГ, подтверждённым ЭХО-КГ - увеличение массы миокарда ЛЖ более чем 120 г/м², толщина МЖП и ЗСЛЖ более 95 перцентиля), как проявления вовлечённости сердечной мышцы в патологический процесс. Известно, что в первую очередь при ожирении страдает липидный обмен. Так, в нашем исследовании нарушения обмена липидов были выявлены у 56 человек (48,3\%). Повышение уровня ОХC - 34 человека (29,3\%): 30 (34,5\%, со средним значением 5,77士0,165 ммоль/л, р<0,05) и 4 (13,8\%; от 5,6 до 6,4 ммоль/л) в возрасте от 9 до 17 лет, - преимущественно за счет увеличения ХС ЛПНП (со средним значением 2,94 $\pm 0,11$ ммоль/л, $\mathbf{p}<0,05)$. Повышенная концентрация ТГ определялась у 26 детей (22,4\%): 21 (24,1\%; 2,26士0,287 ммоль/л, р<0,05) и 5 (17,2\%; 
от 1,75 до 3,27 ммоль/л) в возрасте от 9 до 17 лет. Снижение уровня ХС ЛПВП

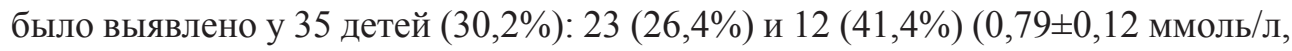
$\mathrm{p}<0,05$ - мальчики и дети старше 16 лет и $1,10 \pm 0,15$ ммоль/л, $\mathrm{p}<0,05$ - девочки старше 16 лет). Кроме того, у 11 человек $(9,5 \%$; все мальчики $(12,6 \%))$ было зафиксировано сочетание повышенных концентраций ТГ и ОХ и в 15 случаях $(12,9 \%)$ - высокого содержания ТГ и сниженного ХС ЛПВП (10 (11,5\%) и 5 $(17,2 \%))$. Достаточно частым спутником ожирения является и гипергликемия, как проявление нарушения обмена углеводов. В нашей работе гипергликемию имели 26 (22,4\%) детей в возрасте от 10 до 16 лет: 20 (23\%, по пробе СГТТ $9,36 \pm 1,09$ ммоль/л, $<<0,05)$ и $6(20,7 \%$, от 8,0 до 9,0 ммоль/л), в том числе 18 человек - впервые выявленную (69\%) и 5 - СД ІІ типа (19\%). Нарушений обмена МК среди девочек не встречалось, но зарегистрировано у 22 мальчиков $(18,9 \%$ всех мальчиков) в виде ГУ $(0,53 \pm 0,024$ ммоль/л, $\mathrm{p}<0,05)$ в возрасте от 11 до 16 лет. Сочетание нарушений липидного обмена и гипергликемии отмечено у 15 детей $(12,9 \%): 11(12,6 \%)$ и $4(13,8 \%)$ в возрасте от 9 до 16 лет. Сочетание ГУ и нарушения обмена липидов выявлено у 5 мальчиков (5,74\%); у 9 мальчиков $(10,3 \%)$ - сочетание ГУ и гипергликемии (возраст детей 12-17 лет). Наличие 3-4-х компонентов в различных комбинациях обменных и регуляционных нарушений определено у 20 детей (17,2\%). У одного ребенка (мальчик 14 лет с IV степенью ожирения) был обнаружен полный вариант МC. 14 человек из 50-ти обследованных (28\%) имели I/I вариант полиморфизма гена АПФ (35\% - все мальчики), 24 человека - I/D (48\%, 18 (45\%) и $6(60 \%)), 12$ человек - D/D $(24 \%, 8$ $(20 \%)$ и $4(40 \%)) .9$ из 12 человек (75\%), гомозигот по D-аллелю (D/D) гена АПФ, считающегося независимым фактором риска развития злокачественных форм АГ, имели стойкое, высокое АД (выше 95 центиля по полу возрасту и росту). Среди ближайших родственников этих детей в 6 случаях из 9 (66,6\%) отмечалась ИБС и имелись жалобы на АГ и кризовые подьёмы АД, приведшие у 4 человек $(66,6 \%)$ к осложнениям в виде геморрагического инсульта и инфаркта миокарда. 38 человек имели W/W вариант полиморфизма гена $\beta_{3}$ - AR $(76 \%, 30$ (75\%) и 8 $(80 \%)), 12$ человек - W/R вариант (24\%, 10 (25\%) и 2 (20\%), R/R варианта не встречалось. У 8 гетерозигот из 12 (66,7\%), имеющих «протективный» R-аллель, не смотря на наличие ожирения II-III степени (66,7\% и 33,3\% соответственно) и повышенного показателя ОТ (100\%), не выявлялось нарушений липидного и углеводного обмена, которые были бы, вполне, ожидаемы. Характерно и то, что у родителей этих детей в 6 случаях из 8 (75\%) также наблюдалось абдоминальное ожирение, начавшее прогрессировать, примерно, в том же возрасте и по схожим закономерностям, и также без диагностированных нарушений липидного и углеводного обмена.

Таким образом, в детском и подростковом возрасте при наличии абдоминального ожирения часто встречаются сопутствующие нарушения обмена липидов (48,3\%), углеводов $(22,4 \%)$, пуриновых оснований $(19 \%)$ и регуляции 
АД (43,1\%- эпизодические, 19,8\%- стойкие нарушения), характерные для МС. Результаты генетического анализа и схожесть клинической картины основных патологических проявлений среди детей и их ближайших родственников (более чем в $66,6 \%$ случаев) позволяет говорить о том, что на процесс формирования и клиническую выраженность перечисленных признаков у детей с ожирением значительное влияние оказывают генетические факторы, лежащие в основе наследственной предрасположенности, заранее определяющей общие черты и особенности будущих признаков. Их выявление помогает объяснить наличие или отсутствие ожидаемых проявлений заболевания, а также заблаговременно сформировать группу риска развития МС и определить возможность и эффективность немедикаментозной и фармакотерапии.

Детям, входящим в группу риска развития $\mathrm{MC}$, как и уже имеющим основные признаки синдрома показана комплексная терапия, объём и методы которой подбираются строго индивидуально и зависят от выраженности и формы заболевания, во многом определяемые генотипом ребёнка.

Основной целью профилактики и лечения является предотвращение или снижение общего риска развития и прогрессирования сердечно-сосудистой заболеваемости характерной для МС. В детском и подростковом возрасте на первый план выходит профилактика формирования и развития составляющих MC. На любом этапе развития заболевания важны мероприятия, направленные на формирование здорового образа жизни, борьбу с избыточной массой тела, перееданием и несбалансированным питанием, оптимизацию двигательной режима, отказ от вредных привычек.

Наиболее эффективным методом воздействия практически на все компоненты МС является борьба с избыточной массой тела. Снижение массы тела на $10-15 \%$ от исходной способствует повышению чувствительности к инсулину, улучшает показатели углеводного и липидного обмена, снижает системную ГИ, и АД. Данные эффекты достигаются путём рационального питания в сочетании с индивидуально подобранной физической нагрузкой. При неудовлетворительном результате возможно сочетание с медикаментозной терапией. Успешно применяется орлистат (ксеникал) - ингибитор панкреатической и кишечной липазы, стабилизирующий массу тела, улучшающий показатели липидного и углеводного обмена, разрешён с 12 лет по 120 мг 3 раза в день. При диагностированной гипергликемии на фоне ИР препаратом выбора является метформин (сиофор/глюкофаж) - бигуанид, повышающий чувствительность тканей к инсулину, способствующий стабилизации и снижению массы тела и оказывающий гипотензивный эффект, разрешён с 10-12 лет по 500-1000 мг 1 раз в день [1,12-14].

При выраженной дислипидемии детям и подросткам назначаются гиполипидемические препараты. При смешанной и изолированной гиперхолестеринемии применяют эссенциальные фосфолипиды, анионообменные смолы, 
антиоксиданты (элькар, кудесан) пробукол, статины (разрешены с 12 лет). При гипертриглицеридемии - препараты, содержащие $\omega$-3-полиненасыщенные жирные кислоты (омакор) и фибраты (разрешены с 12 лет) $[1,12,13,15]$. Кроме того, неплохие результаты по нормализации липидного спектра были получены на фоне применения про-и пребиотиков, таких как бифиформ®малыш (содержащий лакто- и бифидобактерии) и дюфалак® (содержащий лактулозу), что объясняется непосредственным участием нормальной микрофлоры в процессах регуляции обмена липидов.

В лечении пациентов, страдающих АГ, связанной с МС, важен подбор препаратов, не ухудшающих показатели углеводного и липидного обмена. Хорошо себя зарекомендовали ингибиторы АПФ (капотен, ренитек), которые, кроме гипотензивного эффекта, обладают протективным нефро- и кардиоваскулярным эффектом, снижают ИР и разрешены с 10-12 лет по 5-10 мг 1 раз в день $[1,12-15]$. Перспективны в этом плане и агонисты I-имидазолиновых рецепторов (моксонидин (физиотенз)), снижающие системное сосудистое сопротивление и АД, оказывающие нефро- и кардиопротективное действие $[12,14]$. Препаратами выбора, как у детей, так и у взрослых, остаются: диуретики (индапамид/арифон - по 1,5 мг/сут, верошпирон), селективные $\beta_{1}$-адреноблокаторы (корвитол, небилет, биспролол), антагонисты кальция (верапамил/нифедипин) $[12,14,15]$.

\section{Список использованной литературы}

Буторова С.А. // Русс. Мед. Журнал. - 2001. - Т. 9, №2. - С. 56-61.

Старкова Н.Т., Дворяшина И.В. // Тер. архив. - 2004. - №10. -С. 54-58.

Camus J.P. // Rev Rhumat. - 1966. - N33. - P. 10-14.

Avogaro P., Crepaldi G., Enzi G., Tiengo A. // Acta Diabetol. Lat. - 1967. - N4. - P. 572-590.

Reaven G.M. // Diabetes. - 1988. - N37. - P. 1596-1607.

Зимин Ю.В. // Кардиология. - 1999. -№8. - С. 37-41.

Bjorntorp P. // Obes. Res. - 1991. - Vol. 1, N3. - P. 206-222.

The International Diabetes Federation (IDF) consensus definition of the Metabolic Syndrome in children and adolescents // ( International Diabetes Federation - 2007. - P. 1-22

Alberti G., Zimmet P., Shaw JE. // Lancet. - 2005. - N5. - P. 1059-1062

Zimmet P., Alberti G, Kaufman F. at all // Pediatric Diabetes. - 2007. - Vol. 8, N5. - P. 299306.

Katmarzyk P.T. et al. // Pediatrics. - 2004. - N114. - P. 198.

Дороднева Е.Ф., Пугачёва Т.А., Медведева И.В. // Терапевтический архив.- 2002.- №10.C. 7-12.

Гинзбург М.М., Крюков Н.Н. Ожирение. Влияние на развитие метаболического синдрома. Профилактика и лечение. Медпрактика - М, Москва 2002, 128c. 
Кобалава Ж.Д., Толкачёва В.В. и соавт. Клинико-генетические аспекты нарушений углеводного обмена и эффективность их коррекции моксонидином и метформином у больных артериальной гипертонией. Обзоры клинической кардиологии 2006; №4;14-20.

Самсыгина Г.А., Щербакова М.Ю. Кардиология и ревматология детского возраста. М.:ИД Медпрактика-М, 2004, 744 с. 